\title{
SIMPLE AND RAPID METHOD FOR ISOLATING ANTHOCYANIN FROM WILD MULBERRY (MORUS NIGRA L.)
}

\author{
Rollando Rollando*, Christopher Daniel Kurniawan, Ririn Nurdiani, Sophia Yusnita \\ Wahyu Timur, Paulina Genoveva Moza \\ ${ }^{1}$ Program of Pharmacy, Faculty of Science and Technology, Ma Chung University, 65151 \\ Malang, East Java, Indonesia.
}

Received Deccember 19, 2018; Accepted March 24, 2019

\begin{abstract}
Wild mulberry (Morus nigra L.) is a kind of berries that has a high content of anthocyanin pigment. Anthocyanin is a natural pigment that has good biological activity so that widely be used as both food and drug ingredients. There are many studies conducted that have isolation anthocyanin from mulberry extract, but most of them used various expensive methods and the process included several steps that make them not cost-effective nor time-efficient. This research was conducted in order to do an isolation of anthocyanin from wild mulberry through a single step. The extraction of compounds was done by maceration and the isolation was done by thin layer chromatography method. The isolation product was identified with reagents, consisting of ferric chloride and sodium hydroxide, and with spectrophotometry methods, consisting of UV-Vis and infrared spectrophotometry. As result, this research was able to isolate anthocyanin from wild mulberry fruit by thin layer chromatography method. The identification with spectrophotometry methods indicated that the isolated compound hypothetically was anthocyanidin-3-O-rutinoside.
\end{abstract}

Keywords: anthocyanin; isolation; thin layer chromatography; mulberry fruit; Morus nigra L.

\section{INTRODUCTION}

The increasing of education level in society has led to a higher awareness to a healthy lifestyle. Food, as one of the important lifestyle components, plays a crucial role in health since the body receives nutrients from the food intake. Food contains several chemical constituents including colorant. The use of colorant has shifted from synthetic and insect-base colorant to natural colorant. One natural colorant that promises good use as a safe food colorant and has good antioxidant activity is anthocyanin (Kendrick, 2016).

Anthocyanin is a water-soluble pigment due to the hydroxyl rich chemical structure. It is classified into the flavonoid group and has glycosides attached on the second aromatic ring (Pervaiz et al., 2017). It can be found in various parts of plant which are blue, red, or purple color. A positive charged oxygen that makes it become more reactive in scavenging free electrons in free radical compounds. As a good source of antioxidants, anthocyanin has been used widely as supplements and food additives (Khoo et al., 2017).

Beside its antioxidant activity, anthocyanin has the potential to be used as an active pharmaceutical ingredient. Scientific study showed that anthocyanin has anticancer activities on HepG2 (Yan et al., 2017), SKHep1 (Thi and Hwang, 2018), and MCF-7 cells (Roobha et al., 2011). Other researchers found that anthocyanin has a potency as an inhibitor for various enzyme, including monoamine oxidase A, tyrosinase, $\alpha$ glucosidase and dipeptidyl peptidase-4, as well as enzyme that is responsible for chronic and degenerative diseases (Cásedas et al., 2017). Research has shown that enzymatic

*Corresponding author: Rollando Rollando

Email: ro.llando@machung.ac.id 
inhibition activity of anthocyanin acts on cyclooxygenase-2 which is responsible for inflammatory responses in the body (Miguel, 2011).

Berries provide a promising resource for anthocyanin pigment. Mulberry (Morus nigra L.) is a kind of berries that grows in tropical regions, including Indonesia. It contains a high amount of anthocyanin. Previously, one anthocyanin characterization study on mulberry showed that the fruit extract of mulberry contained cyanidin-3-O-glycoside and cyanindin-3-O-rutinose. They were identified with spectrometry methods on 527 and $529 \mathrm{~nm}$, respectively (Sitepu et al., 2016). Additionally, anthocyanins can also be prepared using HPLC-MS with UV detectors and ESI interfaces using positive ion models in MS systems (Huang et al., 2012).

The promising use of anthocyanin has led to an increasing demand. Common methods that are used to extract anthocyanin are costly with a great expense in both time and money. The extraction of anthocyanin mostly has used nitrogen to eliminate water from the plant material (Bondre et al., 2012; Huang et al., 2012). Generally, the isolation of anthocyanin is conducted by either HPLC, using the solvents of acetonitrile: water $(1: 1 \mathrm{v} / \mathrm{v})$ containing $2 \%$ formic acid and aqueous $2 \%$ formic acid. The gradient was from 6 to $10 \%$ $\mathrm{B}$ for $4 \mathrm{~min}$, from 10 to $25 \% \mathrm{~B}$ for $8 \mathrm{~min}$, isocratic $25 \%$ B for $1 \mathrm{~min}$, from 25 to $40 \%$ for $7 \mathrm{~min}$, from 40 to $60 \%$ for $15 \mathrm{~min}$, from 60 to $100 \%$ for $5 \mathrm{~min}$, from 100 to $6 \%$ for $5 \mathrm{~min}$, at a flow rate of $1.0 \mathrm{ml} / \mathrm{min}$. Isolation process also used the multi-step conventional method, including column chromatography and thin layer chromatography (Huang et al., 2012). Thus, a cost-effective and time-efficient method needs to be discovered. This research aimed to isolate anthocyanin from wild mulberry fruit extracts through a single step thin layer chromatography.

\section{METHODS}

\section{Material and chemicals}

Analytical balance (Ohaus ${ }^{\circledR}, 0,001 \mathrm{~g}$ ), museums jar with glass plate (Duran ${ }^{\circledR}$, 210x100mm), membrane filter (Sartorius ${ }^{\circledR}$,
0,22 $\mu \mathrm{m}), \quad$ UV-Vis and Infrared Spectrophotometer (Jasco®, Japan), hand blender (Panasonic $\AA)$, rotary evaporator (IKA®, RV10), wild mulberries was collected from Karang Besuki District, silica gel 60 $\mathrm{GF}_{254}$ TLC plate (Merck ${ }^{\mathrm{TM}}$, Germany), silica gel $60 \mathrm{G}$ for Preparative TLC (Merck TM, Germany), ethyl acetate, ethanol 96\%, water, methanol (PT Panadia Corporation Indonesia $\mathrm{TM}$, technical grade), and glacial acetic acid, chloroform (Merck ${ }^{\mathrm{TM}}$, analytical grade).

\section{Extraction of mulberry fruits}

The extraction method followed the previous research conducted by Huang et al. (2012) with a few modifications. Mulberry fruit was washed and cleaned with water and then sorted to remove the remaining stalks and other impurities. The sorted sample was crushed with hand-blender so that a pulp was formed. The pulp was macerated twice with a solvent (1:3), which consisted of methanol and glacial acetic acid (99:1), for 24 hours. The maceration process was done in an ice bath and with minimum light exposure. The maceration product was filtered to obtain the filtrates. In order to remove smaller particles, the filtrates were centrifuged on $4000 \mathrm{rpm}$ for 5 minutes. An evaporation process was done by rotary evaporator on $60^{\circ} \mathrm{C}$ under vacuum conditions. The saturated filtrated result went through further evaporation process with a water bath until a thick extract was formed.

\section{Isolation of anthocyanin pigment}

Purification of anthocyanin was done through thin layer chromatography methods. The extract was diluted in methanol to get a 10 $\mathrm{mg} / \mathrm{ml}$ solution, then filtered with a membrane filter to remove insoluble particles. After that, the solution was applied to an activated TLC plate. Activation of TLC plate was done by heating the plate in the oven at $115^{\circ} \mathrm{C}$ for 15 minutes. TLC was done by eluting the plate with several eluents as shown in Table II. Eluted spots were taken from the plate, then washed with methanol:chloroform (1:1). Those filtrates were evaporated to become dry under room temperature to be identified. 


\section{Identification compound}

Initial identification of anthocyanin was done by simple qualitative colorimetry methods. An amount of $10 \mathrm{mg}$ extract was diluted with $10 \mathrm{ml}$ methanol. The diluted extract was added by $1.0 \% \mathrm{FeCl}_{3}$ and $2.0 \mathrm{~N}$ $\mathrm{NaOH}$ solution separately. A color change to purple after addition of $\mathrm{FeCl}_{3}$ and blue after addition of $\mathrm{NaOH}$ indicated that the solution contains anthocyanin. Isolates of anthocyanin were diluted in methanol:chloroform $(1: 1)$. The solution was read with UV-Vis and IR spectrophotometer to obtain the spectra data.

\section{RESULTS AND DISCUSSION}

Extraction of mulberry through maceration gave a result of crude extract with dark red color. The addition of glacial acetic acid in the solvent had a functional purpose to maintain the stability of anthocyanin during the extraction and storage. A higher $\mathrm{pH}$ of solution can cause a color change of anthocyanin from red, purple, or blue. The mechanism is described in Figure 1 (Wahyuningsih et al., 2017). As the extract was thickening, the weight of the extract was measured and showed a yield of 15, 30 gram or $5.1 \%$ relative from the amount of plant material. The initial identification was conducted to ensure that the extraction method gave an extract containing anthocyanin. Table I shows the result of the initial identification using $\mathrm{FeCl}_{3}$ and $\mathrm{NaOH}$ as reagents.

Table I. Anthocyanin Initial Identification

\begin{tabular}{ccc}
\hline Sample & Reagent & Result \\
\hline Mulberry Fruit & $1 \% \mathrm{FeCl}_{3}$ & Purple \\
\cline { 2 - 3 } Extract & $2,0 \mathrm{~N} \mathrm{NaOH}$ & Blue \\
\hline
\end{tabular}

The result of initial identification showed that the mulberry fruit extract contains anthocyanin. A change of color to purple after addition of ferric chloride solution was the expression of ferric-phenol complex from polyphenol groups in anthocyanin (Obouayeba et al., 2015). Figure 3 shows the formation reaction of ferric-phenol complex. Meanwhile, blue color was expressed since the base condition reacts with anthocyanin, causing a form of negatively charged ions. This was the specific color test for anthocyanin.

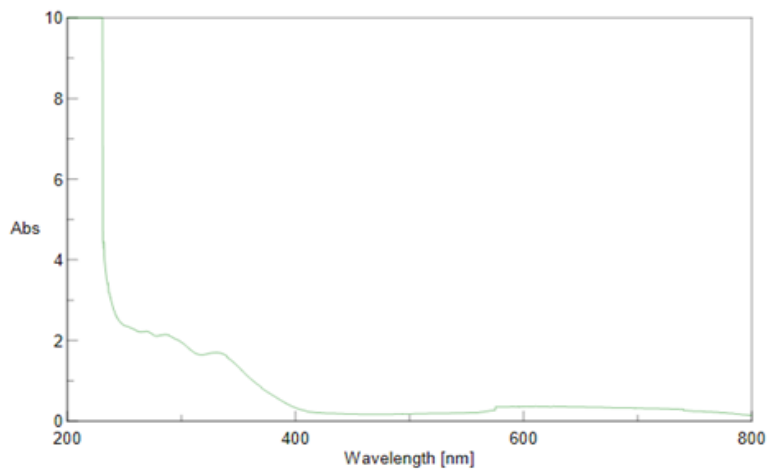

Figure 2. UV-Vis spectrum of second isolate

Since the main purpose of this research was to find cost effective method, the isolation was conducted by thin layer chromatography. The separation of anthocyanin was done on preparative plate which was coated with silica gel 60. Table II shows the eluent used on the TLC method. The two spots that separated shown a difference in color, but had a very close $\mathrm{Rf}$ value. Both of the spots appeared on $\mathrm{Rf}$ of 0.81 and 0.82 , respectively. Both isolates obtained from TLC method were separated from silica gel by diluting them in methanolchloroform solution. The first isolate's weight was $46 \mathrm{mg}$ and the second was $139 \mathrm{mg}$. Spectrophotometry was conducted on the second isolate since red color was believed to express the stable anthocyanin (Wahyuningsih et al., 2017). The isolate was diluted with $2 \mathrm{ml}$ methanol-chloroform to be measured by spectrophotometer. Figure 2 shows the UVVis spectrum data of the second isolate.

Table II. Separation of Anthocyanin using TLC method

\begin{tabular}{cc}
\hline Eluent Composition & Result \\
\hline Ethanol:Water:Acetic Acid (4:5:1) & 2 spots \\
\hline Ethanol:Water:Acetic Acid $(4,5: 5: 0,5)$ & - \\
\hline
\end{tabular}

Ethanol:Water:Acetic Acid (4:2:1)

EtOAc: Ethanol:Water (65:25:10)

The UV-Vis spectrum shows two peaks around 280 and $560 \mathrm{~nm}$. Based on the previous study conducted by Qin et al., anthocyanidin-3-O-rutinoside had maximum wavelength on 281.1 and $524.7 \mathrm{~nm}$ (Qin et al., 2010). Similarity between those spectra 
hypothetically indicated that the second isolate was an anthocyanidin-3-O-rutinoside. There was slight differences between the results that could be caused by the effect of different solvents used on each research (Field et al., 2008). This research used methanolchloroform solvent, while the previous study used acetate buffer ( $\mathrm{pH}$ 3.6). It means that the solvent from the previous study was more polar, thus causing a detection on shorter wavelength.<smiles></smiles><smiles>COC1=Cc2c(O)cc(O)cc2OC1C1C=CC(=O)C(O)=C1</smiles>

$$
\begin{aligned}
& \begin{array}{l}
\text { violet solution } \\
(\mathrm{pH}=6-8)
\end{array} \\
& +\mathrm{H}^{+}
\end{aligned}
$$<smiles>CCOC1=Cc2c(O)cc(O)cc2OC1C1C=CC(=O)C([O-])=C1</smiles>

blue solution $(\mathrm{pH}>9)$

Figure 1. Effect of $\mathrm{pH}$ change on anthocyanin solution color

The isolation of anthocyanin compounds was previously done by Huang et al. 2012. In his research, anthocyanins were identified and quantified using HPLC/DAD and HPLC/ESI/MS. Cyanidin-3-galactoside was the major compound, making up to $93 \%$ of the total anthocyanin content. The content of Cyanidin-3-galactoside reached $23.7 \pm 3.2 \mathrm{mg}$ $100 \mathrm{~g}^{-1}$ fresh weight. The research used HPLC/DAD and HPLC/ESI/MS which are expensive and complicated. This was different in our study, where the isolation of anthocyanin compounds only used TLC preparative with the mobile phase of ethanol:water:acetic acid (4:5:1). Our study used methods that were relatively cheap and simple with a yield of $32.4 \pm 1.3 \mathrm{mg} 100 \mathrm{~g}^{-1}$ fresh weight.<smiles>COc1cc2c(O)cc(O)cc2[o+]c1-c1ccc(O)c(O)c1</smiles>

cyanidin-3-0-rutinoside

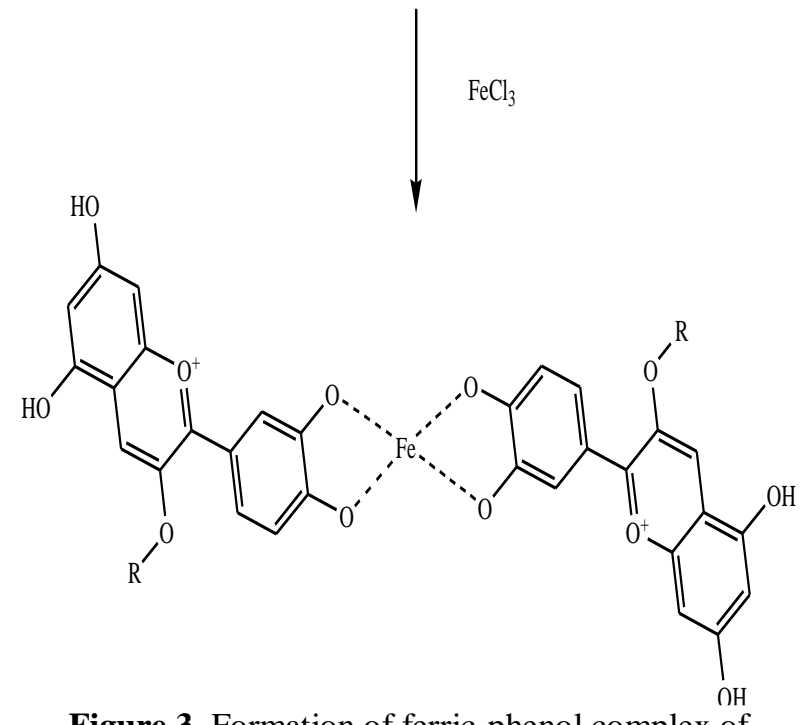

Figure 3. Formation of ferric-phenol complex of cyanidin-3-O-rutinoside

Infrared spectrum shows functional groups in a compound. The diluted second isolate solution was applied to FTIR to be scanned. Figure 4 shows the IR spectrum of second isolate. Infrared spectrum of the second isolate showed peaks on 3310.21; 1640.16; and $1033.66 \mathrm{~cm}^{-1}$. That were similar to the previous study on anthocyanin conducted by Chang et al. The characteristic 
phenol was shown by the peak on $3310.21 \mathrm{~cm}^{-}$ 1; alkene groups from the benzene structure were shown by the peak on $1650.16 \mathrm{~cm}^{-1}$; and alkoxy group was shown by the peak on 1033.66 (Chang et al., 2013). The difference between those spectra were the peaks on 665.32 and $420.41 \mathrm{~cm}^{-1}$ which were the expression of carbon-halogen bonding, especially carbon-chlorine from the chloroform (Field et al., 2008).

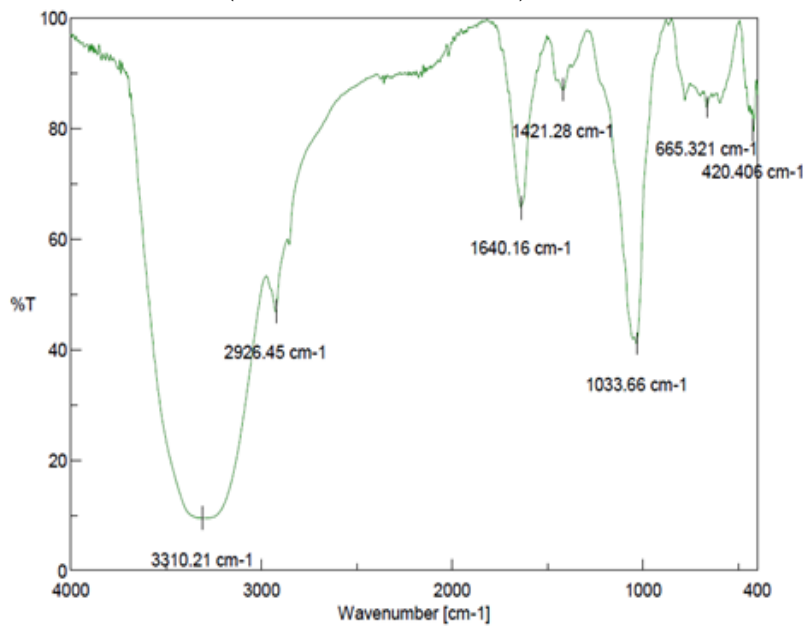

Figure 4. IR spectrum of second isolate

\section{CONCLUSION}

Wild mulberry (Morus nigra L.) obtained from the Karang Besuki District was confirmed to positively contain anthocyanin pigment. Based on the spectra study, the anthocyanin isolated from the fruit was hypothetically an anthocyanidin-3-Orutinoside. This study focused on the isolation of anthocyanin pigment from wild mulberry by using thin layer chromatography method. The result of this study indicates that TLC is a potential method for isolating anthocyanin pigment from wild mulberry fruit.

\section{ACKNOWLEDGEMENT}

Authors are thankful to Ma Chung University for the funding of this research.

\section{REFERENCES}

Bondre S., Patil P., Kulkarni A., and Pillai M.M., 2012. Study on isolation and purification of anthocyanins and its applications as $\mathrm{pH}$ indicator. International Journal of Advanced
Biotechnology and Research, 3(3), 698-702.

Cásedas G., Les F., Gómez-Serranillos M.P., Smith C., and López V., 2017. Anthocyanin profile, antioxidant activity and enzyme inhibiting properties of blueberry and cranberry juices: A comparative study. Food and Function, 8(11), 4187-4193.

Chang H., Kao M.-J., Chen T.-L., Chen C.-H., Cho K.-C., and Lai X-R., 2013. Characterization of Natural Dye Extracted from Wormwood and Purple Cabbage for Dye-Sensitized Solar Cells, International Journal of Photoenergy.

Field L.D., Sternhell S., and Kalman J.R., 2008. Organic Structures from Spectra. 4th ed. Chichester: John Wiley and Sons.

Huang W., Zhang S., Qin G., Wenquan L., and $\mathrm{Wu}$ J., 2012. Isolation and determination of major anthocyanin pigments in the pericarp of $P$. communis L. cv. 'Red Du Comices' and their association with antioxidant activity. African Journal of Agricultural Research, 7(26), 37723780 .

Kendrick A., 2016. Coloring Aqueous Food Types, in: Handbook on Natural Pigments in Food and Beverages: Industrial Applications for Improving Food Color, Elsevier Ltd, 163-177.

Khoo H.E., Azlan A., Tang S.T., and Lim S.M., 2017. Anthocyanidins and anthocyanins: colored pigments as food, pharmaceutical ingredients, and the potential health benefits. Food \& Nutrition Research, 61(1).

Miguel M.G., 2011. Anthocyanins: Antioxidant and/or anti-inflammatory activities. J. App. Pharm. Sci., 1(6), 715.

Obouayeba A.P., Diarrassouba M., Soumahin E.F., and Kouakou H., 2015. Phytochemical Analysis, Purification and Identification of Hibiscus Anthocyanins. Journal of 
Pharmaceutical, Chemical and Biological Sciences, 156-168.

Pervaiz T., Songtao J., Faghihi F., Haider M.S., and Fang J., 2017. Naturally Occurring Anthocyanin, Structure, Functions and Biosynthetic Pathway in Fruit Plants. Journal of Plant Biochemistry \& Physiology, 5(2).

Qin C., Li Y., Niu W., Ding Y., Zhang R., and Shang X., 2010. Analysis and characterisation of anthocyanins in mulberry fruit. Czech Journal of Food Sciences, 28(2), 117-26.

Roobha J., Saravanakumar M., Aravindhan K.M., and Suganya D.P., 2011. In vitro evaluation of anticancer property of anthocyanin extract from Musa acuminate bract. Research in Pharmacy, 1(4), 17-21.

Sitepu R., Brotosudarmo T.H.P., and Limantara L., 2016. Karakterisasi Antosianin Buah Murbei Spesies Morus alba dan Morus cathayana di Indonesia (Anthocyanin Characterization of Morus alba and
Morus cathayana in Indonesia ). Online Journal of Natural Science, 5(2), 158171.

Thi N.D., and Hwang E.S., 2018. Effects of black chokeberry extracts on metastasis and cell-cycle arrest in SKHep1 human liver cancer cell line. Asian Pacific J. Trop. Biomed., 8(6), 285-291.

Wahyuningsih S., Wulandari L., Wartono M.W., Munawaroh H., and Ramelan A.H., 2017. The Effect of $\mathrm{pH}$ and Color Stability of Anthocyanin on Food Colorant. In IOP Conference Series: Materials Science and Engineering. 193(1).

Yan F., Chen Y., Azat R., and Zheng X., 2017. Mulberry Anthocyanin Extract Ameliorates Oxidative Damage in HepG2 Cells and Prolongs the Lifespan of Caenorhabditis elegans through MAPK and Nrf2 Pathways. Oxidative Medicine and Cellular Longevity. 